Supplementary Information

\title{
Facet-Dependent Adsorption and Fractionation of Natural Organic Matter on Crystalline Metal Oxide Nanoparticles
}

\author{
Zelin Shen, ${ }^{\dagger}$ Zhanhua Zhang, ${ }^{\dagger}$ Tong Li, ${ }^{\dagger}$ Qingqian Yao, ${ }^{\dagger}$ Tong Zhang, ${ }^{*}{ }^{\dagger}$ Wei Chen, ${ }^{\dagger}$
}

${ }^{1}$ College of Environmental Science and Engineering, Ministry of Education Key Laboratory of Pollution Processes and Environmental Criteria, Tianjin Key Laboratory of Environmental Remediation and Pollution Control, Nankai University, 38 Tongyan Rd., Tianjin 300350, China

* Corresponding author: Tong Zhang (E-mail: zhangtong@nankai.edu.cn).

Number of pages: 29

Number of tables: 5

Number of figures: 12 
Materials. Suwannee River humic acid standard II (SRHA, 2S101H) and Suwannee River fulvic acid standard II (SRFA, 2S101F) were purchased from the International Humic Substances Society (IHSS). Different-faceted anatase $\mathrm{TiO}_{2}$ nanomaterials, $\mathrm{TiO}_{2}\{101\}$ and $\mathrm{TiO}_{2}\{001\}$, were synthesized using previously reported hydrothermal methods. ${ }^{1,2}$ Different-faceted hematite $\left(\alpha-\mathrm{Fe}_{2} \mathrm{O}_{3}\right)$ nanocrystals, $\alpha-\mathrm{Fe}_{2} \mathrm{O}_{3}\{110\}$ and $\alpha-\mathrm{Fe}_{2} \mathrm{O}_{3}\{001\}$, were synthesized by solvothermal methods reported in the literature. ${ }^{3}$ All reagents used for $\mathrm{TiO}_{2}$ and $\alpha-\mathrm{Fe}_{2} \mathrm{O}_{3}$ synthesis were of AR-grade, obtained from Sigma-Aldrich Chemical Reagent Co. Ltd., Shanghai, China, and used without further purification. All experiments used ultrapure water.

Synthesis of Anatase and Hematite Nanocrystals. The $\{101\}$-faceted anatase $\mathrm{TiO}_{2}$ nanomaterial was prepared using a two-step hydrothermal method. ${ }^{1}$ In the first step, titanium dioxide powder ( $1 \mathrm{~g}$, P25, Sigma) was added to $70 \mathrm{~mL}$ of $\mathrm{KOH}$ solution $(10 \mathrm{M})$ in a $100 \mathrm{~mL}$ Teflon autoclave with magnetic stirring, and then the autoclave was kept at $200{ }^{\circ} \mathrm{C}$ for $48 \mathrm{~h}$. The precipitates were washed with ultrapure water and dried in an oven at $60^{\circ} \mathrm{C}$. In the second step, the prepared powder $(70 \mathrm{mg})$ was hydrothermally treated with $70 \mathrm{~mL}$ ultrapure water in a 100 $\mathrm{mL}$ Teflon autoclave at $170{ }^{\circ} \mathrm{C}$ for $24 \mathrm{~h}$. The white precipitates were collected via centrifugation and finally dried at $110{ }^{\circ} \mathrm{C}$. The sample was denoted as $\mathrm{TiO}_{2}\{101\}$. The $\mathrm{TiO}_{2}$ material that predominantly exposed $\{001\}$ crystal facets was synthesized using previously reported solvothermal methods. ${ }^{2}$ Briefly, $20 \mathrm{~mL}$ of tetrabutyl titanate and $3 \mathrm{~mL}$ of hydrofluoric acid (40\%) were mixed in a $50 \mathrm{~mL}$ Teflon autoclave, and heated at $200{ }^{\circ} \mathrm{C}$ for $24 \mathrm{~h}$. Then, the white precipitates were collected by centrifugation and repeatedly washed with ultrapure water and absolute ethanol. Next, the prepared powder was soaked in a $\mathrm{NaOH}(0.1 \mathrm{M})$ solution overnight to remove fluorine ions, followed by rinsing with ultrapure water. Finally, the white precipitates were collected via centrifugation and dried at $80{ }^{\circ} \mathrm{C}$. The sample was denoted as $\left.\mathrm{TiO}_{2} \_001\right\}$. 
The different-faceted hematite nanocrystals were synthesized using previously reported hydrothermal and solvothermal methods. ${ }^{3}$ For the synthesis of hematite nanorods, 5 mmol of $\mathrm{FeCl}_{3} \cdot 6 \mathrm{H}_{2} \mathrm{O}$ was added to $77 \mathrm{~mL}$ of $0.16 \mathrm{~mol} \mathrm{~L}^{-1} \mathrm{NH}_{4} \mathrm{Cl}$ aqueous solution and then stirred for $2 \mathrm{~h}$. The resulting solution was sealed in a $100 \mathrm{~mL}$ Teflon autoclave, and heated at $120{ }^{\circ} \mathrm{C}$ for $12 \mathrm{~h}$. $\mathrm{FeOOH}$ precipitates were formed and washed thoroughly with ultrapure water and absolute ethanol, and dried overnight in an oven at $50{ }^{\circ} \mathrm{C}$. The $\mathrm{FeOOH}$ powder was then calcined under an atmosphere of air at $500{ }^{\circ} \mathrm{C}$ for $2 \mathrm{~h}$ with a heating rate of $5{ }^{\circ} \mathrm{C} \mathrm{min}^{-1}$ to obtain the hematite phase for use. This sample was referred to as $\alpha-\mathrm{Fe}_{2} \mathrm{O}_{3}\{110\}$. For the synthesis of hematite nanoplates, $4 \mathrm{mmol}$ of $\mathrm{FeCl}_{3} \cdot 6 \mathrm{H}_{2} \mathrm{O}$ was dissolved in $40 \mathrm{~mL}$ absolute ethanol with vigorous stirring. Then, 2.8 $\mathrm{mL}$ ultrapure water and $39 \mathrm{mmol}$ of $\mathrm{CH}_{3} \mathrm{COONa}$ were added successively. The mixture was sealed in a $100 \mathrm{~mL}$ Teflon autoclave and heated at $180{ }^{\circ} \mathrm{C}$ for $12 \mathrm{~h}$. The resulting precipitates were collected via centrifugation and washed with ultrapure water and absolute ethanol several times, and then dried overnight in an oven at $50{ }^{\circ} \mathrm{C}$. This sample was referred to as $\alpha-\mathrm{Fe}_{2} \mathrm{O}_{3}\{001\}$.

After material synthesis, the residua of organic ligands on the as-prepared nanocrystals were examined using Raman spectroscopy and X-ray photoelectron spectroscopy (XPS). Raman spectra were obtained on a Raman spectrometer (RM2000, Renishaw) with an excitation wavelength of $532 \mathrm{~nm}$. Surface chemical composition of the materials were determined on an XPS spectroscope (PHI 5000, VersaProbe), and the binding energies were calibrated using C 1s peak of aliphatic carbon at $284.6 \mathrm{eV}$.

Estimation of Relative Abundance of Exposed Crystal Facets. The geometric models (insets of Figure 1) for the anatase and hematite nanocrystals were established according to the dominant exposed facets identified using high-resolution transmission electron microscopy 
(HRTEM) analysis, and the averaged size measurements on the transmission electron microscopy (TEM) images. The detailed procedures for calculating the relative abundance of the exposed facets are as follows:

$\mathrm{TiO}_{2}\{101\}$ nanoparticle (Figure 1a) was composed of eight equivalent $\{101\}$ facets with nearly $100 \%$ exposure of the $\{101\}$ facet of anatase. As shown in Scheme S1, the relative abundance of $\{101\}$ is represented as $\% S_{\{101\}}=100 \%$.

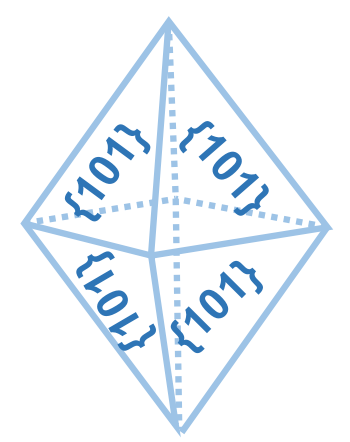

Scheme S1 Geometrical model of $\mathrm{TiO}_{2}\{101\}$ nanoparticle

$\left.\mathrm{TiO}_{2} \_001\right\}$ nanosheet (Figure 1b) was composed of two symmetric $\{001\}$ facets on the basal surfaces and eight equivalent $\{101\}$ facets on the side surfaces. According to previous literature, ${ }^{4}$ the relative abundance of $\{001\}\left(\% S_{\{001\}}\right)$ and $\{101\}\left(\% S_{\{101\}}\right)$ was calculated using equation (S1) and (S2), respectively.

$$
\begin{aligned}
& \% S_{\{001\}}=\cos \theta /\left(\cos \theta+(1-h /(a \times \tan \theta))^{-2}-1\right)=88.7 \% \\
& \% S_{\{101\}}=100 \%-\% S_{\{001\}}=11.3 \%
\end{aligned}
$$

where the measurements of $a$ and $h$ were shown in Scheme S2, and $\theta$ was the angle between $\{101\}$ and $\{001\}$ of anatase $\left(68.3^{\circ}\right) .^{5}$ 


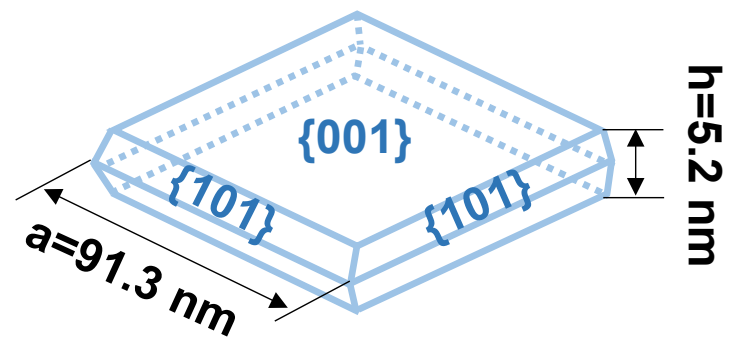

Scheme S2 Geometrical model of $\mathrm{TiO}_{2}\{001\}$ nanosheet

$\alpha-\mathrm{Fe}_{2} \mathrm{O}_{3}\{\{110\}$ nanorod (Figure 1c) was composed of two symmetric $\{001\}$ facets on the basal surfaces and two equivalent $\{110\}$ facets, two equivalent $\{120\}$ facets, and two equivalent $\{210\}$ facets on the side surfaces. The relative abundance of different facets (i.e., $\% S_{\{110\}}, \% S_{\{001\}}$ and $\left.\% S_{\{120\}+\{210\}}\right)$ was calculated according to equation (S3), (S4) and (S5), respectively.

$$
\begin{aligned}
& \% S_{\{110\}}=(a \times h \times 2) /[(a \times h \times 2)+((a+b) \times(c / 2) / 2 \times 4)+(d \times h \times 4)]=36.1 \% \\
& \% S_{\{001\}}=((a+b) \times(c / 2) / 2 \times 4) /[(a \times h \times 2)+((a+b) \times(c / 2) / 2 \times 4)+(d \times h \times 4)]=58.3 \% \\
& \% S_{\{120\}+\{210\}}=(d \times h \times 4) /[(a \times h \times 2)+((a+b) \times(c / 2) / 2 \times 4)+(d \times h \times 4)]=5.6 \%
\end{aligned}
$$

where the measurements of $a, b, c, d$, and $h$ were shown in Scheme S3.

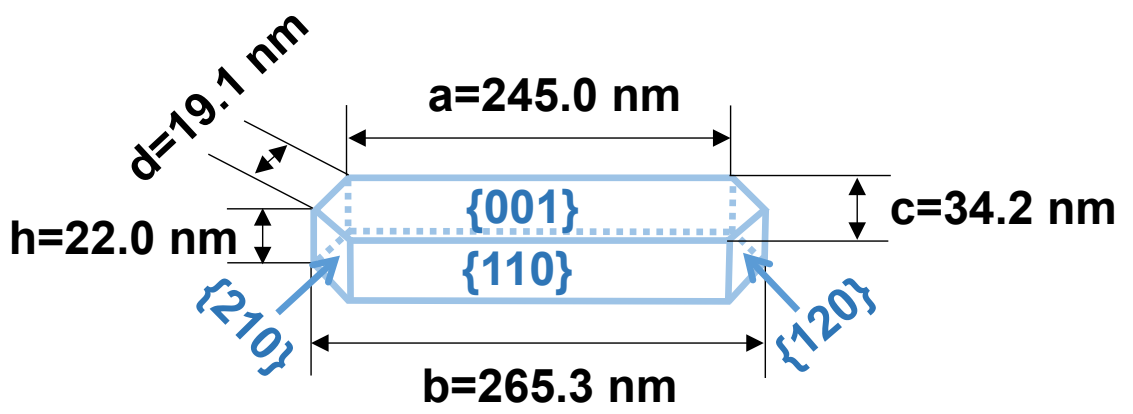

Scheme S3 Geometrical model of $\alpha-\mathrm{Fe}_{2} \mathrm{O}_{3}\{110\}$ nanorod

$\alpha-\mathrm{Fe}_{2} \mathrm{O}_{3}\{001\}$ nanoplate (Figure 1d) was composed of two symmetric $\{001\}$ facets on the basal surfaces and six equivalent $\{102\}$ facets on the side surfaces. The relative abundance of $\{001\}\left(\% S_{\{001\}}\right)$ and $\{102\}\left(\% S_{\{102\}}\right)$ was calculated according to equation (S6) and (S7), 
respectively.

$$
\begin{aligned}
& \% S_{\{001\}}=((a+b) \times \sin (\theta / 2) \times b / 2 \times 4) /[((a+b) \times \sin (\theta / 2) \times b / 2 \times 4)+(b \times c \times 6)]=83.1 \% \\
& \% S_{\{102\}}=(b \times c \times 6) /[((a+b) \times \sin (\theta / 2) \times b / 2 \times 4)+(b \times c \times 6)]=16.9 \%
\end{aligned}
$$

where the measurements of $a, b$, and $c$ were shown in Scheme S4, and $\theta$ was the angle of a regular hexagon $\left(120^{\circ}\right)$.

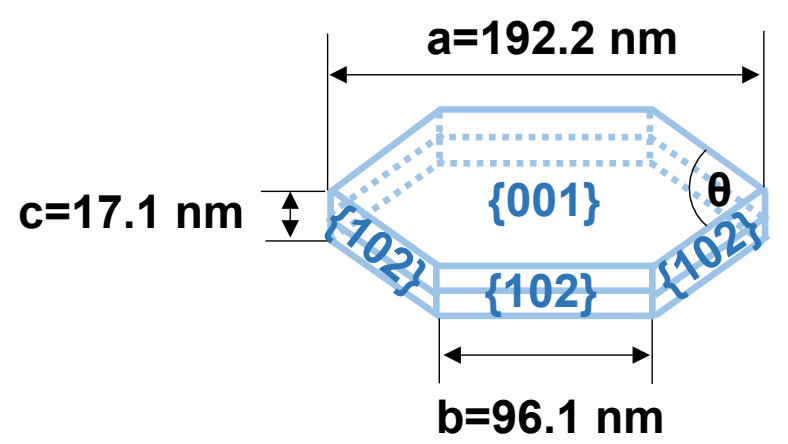

Scheme $\mathbf{S 4}$ Geometrical model of $\alpha-\mathrm{Fe}_{2} \mathrm{O}_{3}\{001\}$ nanoplate

Density Functional Theory (DFT) Calculations. All the calculations was performed within the framework of the density functional theory as implemented in the Vienna ab initio Software Package (VASP 5.3.5) code within the Perdew-Burke-Ernzerhof (PBE) generalized gradient approximation and the projected augmented wave (PAW) method. ${ }^{6-9}$ The cutoff energy for the plane-wave basis set was set to $400 \mathrm{eV}$. The $2 \times 3$ supercell of the anatase (101) surface including 3 layers, $2 \times 2$ supercell of the anatase (001) surface including 5 layers, $2 \times 2$ supercell of the hematite (110) surface including 3 layers and $2 \times 2$ supercell of the hematite (001) surface including 4 layers models were constructed to simulate the anatase and hematite adsorbents in this work. A vacuum layer of $15 \AA$ was introduced to avoid interactions between periodic images. The Brillouin zone of the surface unit cell was sampled by Monkhorst-Pack (MP) grids, with different k-point mesh for anatase and hematite structure optimizations. ${ }^{10}$ The anatase (101) surface was determined by $2 \times 3 \times 1$ Monkhorst-Pack grid. The anatase (001) surface was 
determined by $3 \times 3 \times 1$ Monkhorst-Pack grid. The hematite (110) and hematite (001) surface were determined by $2 \times 2 \times 1$ Monkhorst-Pack grid. With regard to the strong correlation between the electrons in $\mathrm{Ti}$ and $\mathrm{Fe}$, the on-site Coulomb repulsion correction term of $U$ within the Hubbard scheme $(\mathrm{PBE}+U)$ was applied in this work. The effective $U_{\text {eff }}$ values for Ti and Fe were set to 3 and $4 \mathrm{eV}$, which are consistent with the previous research. ${ }^{11,12}$ The convergence criterion for the electronic self-consistent iteration and force was set to $10^{-5} \mathrm{eV}$ and $0.01 \mathrm{eV} / \AA$, respectively. The adsorption energy $\left(\Delta E_{\mathrm{ads}}\right)$ was calculated using equation (S8):

$$
\Delta E_{\text {ads }}=E_{\text {total }}-E_{\text {adsorbent }}-E_{\text {adsorbate }}
$$

where $\Delta E_{\text {total }}$ represents the total energies of the system, $E_{\text {adsorbent }}$ is the energy of the empty surface of nanocrystals, and $E_{\text {adsorbate }}$ is the energy of the adsorbate in the gas phase.

For assessing the surface hydrophobicity of different exposed facets of anatase and hematite, ice-like water bilayers adsorbing over the crystalline facets were built to estimate the contact angle $\theta$ according to a previously established model. ${ }^{13,14}$ The contact angle $\theta$ was estimated using equation (S9):

$$
\cos (\theta)=\frac{-\Delta E_{\mathrm{ads}}^{\mathrm{ice}}(\text { bilayer })}{A \gamma_{\text {ice }}}
$$

where $\gamma_{\text {ice was }}$ the surface energy of ice, $\Delta E_{\text {ads }}^{\text {ice }}$ was the adsorption energy of ice water, and $A$ was the surface area of the crystalline facets.

Based on the estimated values of the contact angle $\theta$, the work of adhesion $\left(W_{\mathrm{SL}}\right)$ and surface free energy $\left(\gamma_{\mathrm{S}}\right)$ were calculated using Young-Dupré equation ${ }^{15,16}(\mathrm{~S} 10)$ and Neumann's equation ${ }^{17}$ (S11), respectively:

$$
\begin{aligned}
& W_{\mathrm{SL}}=\gamma_{\mathrm{LG}}(1+\cos \theta) \approx \gamma_{\mathrm{L}}(1+\cos \theta) \\
& W_{\mathrm{SL}}=2 \sqrt{\gamma_{\mathrm{LG}} \gamma_{\mathrm{SG}}} e^{-\beta\left(\gamma_{\mathrm{LG}}-\gamma_{\mathrm{SG}}\right)^{2}} \approx 2 \sqrt{\gamma_{\mathrm{L}} \gamma_{\mathrm{S}}} e^{-\beta\left(\gamma_{\mathrm{L}}-\gamma_{\mathrm{S}}\right)^{2}}
\end{aligned}
$$


where $W_{\mathrm{SL}}$ was the free energy cost to separate water from the crystalline facets, $\gamma_{\mathrm{LG}}$ and $\gamma_{\mathrm{SG}}$ were the interfacial energies (S: solid phase, L: liquid phase, G: gas phase), $\gamma_{L}$ was the surface free energy (surface tension) of water, $\gamma_{\mathrm{S}}$ was the surface free energy of the crystalline facets, and $\beta$ was a universal constant with the value of $0.0001247 \mathrm{~m}^{4} \mathrm{~mJ}^{-2}{ }^{18}$ 
Table S1. Selected physicochemical properties of different-faceted $\mathrm{TiO}_{2}$ and $\alpha-\mathrm{Fe}_{2} \mathrm{O}_{3}$ nanocrystals.

\begin{tabular}{|c|c|c|c|c|c|c|c|c|c|c|}
\hline \multirow{2}{*}{ Nanocrystals } & \multirow{2}{*}{$\begin{array}{c}\mathrm{SA}_{\mathrm{BET}}{ }^{a} \\
\left(\mathrm{~m}^{2} / \mathrm{g}\right)\end{array}$} & \multicolumn{3}{|c|}{ Particle size (nm) } & \multirow{2}{*}{$\begin{array}{c}\text { Crystalline } \\
\text { phase }^{c}\end{array}$} & \multirow{2}{*}{\multicolumn{3}{|c|}{ Exposed crystal facets ${ }^{d}$}} & \multirow{2}{*}{$\mathrm{pH}_{\mathrm{pzc}}{ }^{e}$} & \multirow{2}{*}{$\begin{array}{c}\text { Water } \\
\text { contact } \\
\text { angle } \\
\text { (deg) }\end{array}$} \\
\hline & & Length $^{b}$ & Width $^{b}$ & Thickness ${ }^{b}$ & & & & & & \\
\hline $\mathrm{TiO}_{2}\{101\}$ & 13.2 & $314.8 \pm 53.6$ & $120.1 \pm 16.0$ & - & anatase & $\begin{array}{c}100.0 \% \\
\{101\}\end{array}$ & - & - & 6.0 & 11.3 \\
\hline $\mathrm{TiO}_{2} \_\{001\}$ & 89.4 & $91.3 \pm 17.8$ & $91.3 \pm 17.8$ & $5.2 \pm 0.4$ & anatase & $\begin{array}{l}11.3 \% \\
\{101\}\end{array}$ & $\begin{array}{l}88.7 \% \\
\{001\}\end{array}$ & - & 6.0 & 15.8 \\
\hline$\alpha-\mathrm{Fe}_{2} \mathrm{O}_{3} \_\{110\}$ & 24.4 & $265.3 \pm 54.1$ & $34.2 \pm 9.5$ & $22.0 \pm 4.3$ & hematite & $\begin{array}{l}58.3 \% \\
\{001\}\end{array}$ & $\begin{array}{l}36.1 \% \\
\{110\}\end{array}$ & $\begin{array}{c}5.6 \% \\
\{210\}+\{120\}\end{array}$ & 7.7 & 6.2 \\
\hline$\alpha-\mathrm{Fe}_{2} \mathrm{O}_{3}\{001\}$ & 20.5 & $192.2 \pm 10.5$ & $192.2 \pm 10.5$ & $17.1 \pm 2.8$ & hematite & $\begin{array}{l}83.1 \% \\
\{001\}\end{array}$ & $\begin{array}{l}16.9 \% \\
\{102\}\end{array}$ & - & 7.7 & 30.0 \\
\hline
\end{tabular}

${ }^{a}$ Measured using the Brunauer-Emmett-Teller (BET) method.

${ }^{b}$ The particle sizes were assessed by measuring 100 particles on the TEM images (Figure 1) using ImageJ software, and were presented as “mean \pm standard deviation".

${ }^{c}$ Analyzed using X-ray diffraction (XRD) spectroscopy (Figure S1) and Raman spectroscopy (Figure S3).

${ }^{d}$ Estimated according to the averaged size measurements and the geometric models of the nanocrystal established using HRTEM (Figure 1) and TEM

(Figure 1) analysis.

${ }^{e}$ Assessed according to $\zeta$ potential measurements at different $\mathrm{pH}$ conditions (Figure S8). 
Table S2. Calculated parameters of surface hydrophobicity, free energy and atomic arrangement for different facets of anatase and hematite nanocrystals.

\begin{tabular}{lccccc}
\hline \multirow{2}{*}{ Nanocrystals } & Facets & $\theta_{\mathrm{DFT}}{ }^{a}(\mathrm{deg})$ & $W_{\mathrm{SL}}{ }^{b}\left(\mathrm{~mJ} \mathrm{~m}^{-2}\right)$ & $\gamma_{\mathrm{S}}{ }^{c}\left(\mathrm{~mJ} \mathrm{~m}^{-2}\right)$ & $d_{\mathrm{Me}-\mathrm{Me}}{ }^{d}(\AA)$ \\
\hline \multirow{2}{*}{ Anatase } & $\{101\}$ & 29.1 & 135 & 64.2 & $3.79-5.47$ \\
& $\{001\}$ & 42.7 & 125 & 57.2 & $3.75-3.80$ \\
\hline \multirow{2}{*}{ Hematite } & $\{110\}$ & 21.8 & 139 & 67.3 & $5.40-7.41$ \\
& $\{001\}$ & 46.5 & 122 & 55.1 & 5.04 \\
\hline
\end{tabular}

${ }^{a}$ Water contact angle estimated with DFT calculations.

${ }^{b}$ Work of adhesion estimated according to Young-Dupré equation.

${ }^{c}$ Surface free energy estimated according to Young-Dupré equation and Neumann's equation.

${ }^{d}$ Distance between adjacent unsaturated metal atoms. 
Table S3. Model parameters of the adsorption isotherms for NOM adsorption on different-faceted $\mathrm{TiO}_{2}$ and $\alpha-\mathrm{Fe}_{2} \mathrm{O}_{3}$ nanocrystals.

\begin{tabular}{ccccc}
\hline \multirow{2}{*}{ Nanocrystals } & \multirow{2}{*}{ NOM } & \multicolumn{3}{c}{ Freundlich model } \\
\cline { 3 - 5 } & & $K_{\mathrm{F}}{ }^{a}$ & $1 / n^{b}$ & $R^{2}$ \\
\hline $\mathrm{TiO}_{2}\{101\}$ & \multirow{2}{*}{ SRHA } & 0.091 & 0.234 & 0.930 \\
$\mathrm{TiO}_{2}\{001\}$ & & 0.038 & 0.436 & 0.964 \\
\cline { 3 - 5 } $\mathrm{TiO}_{2}\{101\}$ & \multirow{2}{*}{ SRFA } & 0.078 & 0.168 & 0.946 \\
$\mathrm{TiO}_{2}\{001\}$ & & 0.032 & 0.307 & 0.928 \\
\hline$\alpha-\mathrm{Fe}_{2} \mathrm{O}_{3}\{110\}$ & \multirow{2}{*}{ SRHA } & 0.094 & 0.277 & 0.913 \\
$\alpha-\mathrm{Fe}_{2} \mathrm{O}_{3}\{001\}$ & & 0.015 & 0.703 & 0.989 \\
$\alpha-\mathrm{Fe}_{2} \mathrm{O}_{3}\{110\}$ & \multirow{2}{*}{ SRFA } & 0.083 & 0.270 & 0.913 \\
$\alpha-\mathrm{Fe}_{2} \mathrm{O}_{3}\{001\}$ & & 0.012 & 0.751 & 0.943 \\
\hline
\end{tabular}

${ }^{a}$ The affinity coefficient $\left(\left(\mathrm{mg} \mathrm{C} \mathrm{m}^{-2}\right) /\left(\mathrm{mg} \mathrm{C} \mathrm{L}^{-1}\right)^{1 / n}\right)$.

${ }^{b}$ The Freundlich nonlinearity index (dimensionless). 
Table S4. Calculated parameters of adsorption configurations of low-molecular-weight carboxyl-containing organic compounds on different facets of hematite nanocrystals.

\begin{tabular}{|c|c|c|c|c|}
\hline Adsorbates & Facets & $\begin{array}{c}\text { Adsorption } \\
\text { configurations }^{a}\end{array}$ & $\Delta E_{\mathrm{ads}}^{b}(\mathrm{eV})$ & $\mathrm{R}_{\mathrm{C}-\mathrm{Fe}}{ }^{c}(\AA)$ \\
\hline \multirow{4}{*}{ Oxalic acid } & \multirow{2}{*}{110} & $\mathrm{M}-\mathrm{M}$ & 0.04 & 2.97 \\
\hline & & $\mathrm{B}-\mathrm{B}$ & -0.47 & $3.04,3.05$ \\
\hline & \multirow{2}{*}{001} & $\mathrm{M}-\mathrm{M}$ & 0.08 & 3.01 \\
\hline & & $\mathrm{B}-\mathrm{B}$ & -0.08 & $3.32,3.18$ \\
\hline \multirow{8}{*}{ Aspartic acid } & \multirow{2}{*}{110} & M-M I & -2.07 & 3.19 \\
\hline & & B-B I & -2.37 & $2.92,2.88$ \\
\hline & \multirow{2}{*}{001} & M-M I & -1.70 & 2.96 \\
\hline & & B-B I & -2.20 & $3.33,3.14$ \\
\hline & \multirow{2}{*}{110} & M-M II & -2.77 & 3.52 \\
\hline & & B-B II & -2.95 & $3.04,3.01$ \\
\hline & \multirow{2}{*}{001} & M-M II & -2.24 & 2.96 \\
\hline & & B-B II & -2.84 & $3.31,3.13$ \\
\hline
\end{tabular}

${ }^{\bar{a}} \mathrm{M}-\mathrm{M}$ and $\mathrm{B}-\mathrm{B}$ (I: $\alpha$-carboxyl group, II: $\beta$-carboxyl group) represent monodentate-mononuclear and bidentate-binuclear surface complexes, respectively (Figure S9, S10).

${ }^{b}$ Adsorption energy estimated with DFT calculations.

${ }^{c}$ Interatomic distance between carbon and iron atoms (Figure S9, S10). 
Table S5. Spectral characteristics of the three fluorescent components identified using parallel factor (PARAFAC) modeling in this study, with reference to previous research. The maxima wavelengths are presented as excitation/emission wavelengths. Secondary peaks are given in parenthesis.

\begin{tabular}{|c|c|c|c|c|}
\hline \multirow{2}{*}{ Components in this study } & \multirow{2}{*}{ Traditional classification 19,20} & \multicolumn{3}{|c|}{ PARAFAC components in previous studies } \\
\hline & & $\mathrm{Ex} / \mathrm{Em}$ & Description & References \\
\hline \multirow{4}{*}{$\mathrm{C} 1: 230 / 428 \mathrm{~nm}$} & \multirow{4}{*}{ Peak A: 260/380-460 nm } & Region III : $<250 />350 \mathrm{~nm}$ & Fulvic acid-like (hydrophobic acid) & 21 \\
\hline & & $\mathrm{C} 4: 220 / 432 \mathrm{~nm}$ & Fulvic acid-like & 22 \\
\hline & & $\mathrm{P} 2: 240 / 444 \mathrm{~nm}$ & Fulvic-like compounds & 23 \\
\hline & & $\mathrm{C} 2:<260 / 454 \mathrm{~nm}$ & Terrestrial humic-like & 24 \\
\hline \multirow{6}{*}{$\mathrm{C} 2: 265(330) / 464 \mathrm{~nm}$} & \multirow{6}{*}{$\begin{array}{l}\text { Peak A: } 260 / 380-460 \mathrm{~nm} \\
\text { Peak C: } 320-360 / 420-480 \mathrm{~nm}\end{array}$} & Region $\mathrm{V}:>280 />380 \mathrm{~nm}$ & Humic-acid like. & 21 \\
\hline & & $\mathrm{C} 2: 250(300,360) / 458 \mathrm{~nm}$ & Humic-acid like (pyrene family). & 22 \\
\hline & & $\mathrm{C} 1:<260(345) / 462 \mathrm{~nm}$ & Ubiquitous humic-like. & 24 \\
\hline & & C3 : <270(360)/478 nm & & 25 \\
\hline & & $\mathrm{C} 1: 270(365) / 453 \mathrm{~nm}$ & Terrestrial-like humic & 26 \\
\hline & & $\mathrm{C} 2: 240(350) / 470 \mathrm{~nm}$ & & 27 \\
\hline \multirow{6}{*}{ C3: $255(310) / 410 \mathrm{~nm}$} & \multirow{6}{*}{$\begin{array}{l}\text { Peak A: } 260 / 380-460 \mathrm{~nm} \\
\text { Peak M: } 290-312 / 370-420 \mathrm{~nm}\end{array}$} & Region V : >280/>380 nm & Humic-acid like & 21 \\
\hline & & $\mathrm{C} 1: 240(330) / 412 \mathrm{~nm}$ & Humic-acid like & 22 \\
\hline & & $\mathrm{C} 3:<260(305) / 416 \mathrm{~nm}$ & Terrestrial humic-like, fulvic acid-type & 24 \\
\hline & & C3: 255(330)/412 nm & \multirow{3}{*}{$\begin{array}{l}\text { Marine and terrestrial humic materials, } \\
\text { microbial reprocessing }\end{array}$} & 26 \\
\hline & & C3: $250(310) / 400 \mathrm{~nm}$ & & 28 \\
\hline & & $\mathrm{C} 1:<230(290) / 410 \mathrm{~nm}$ & & 27 \\
\hline
\end{tabular}



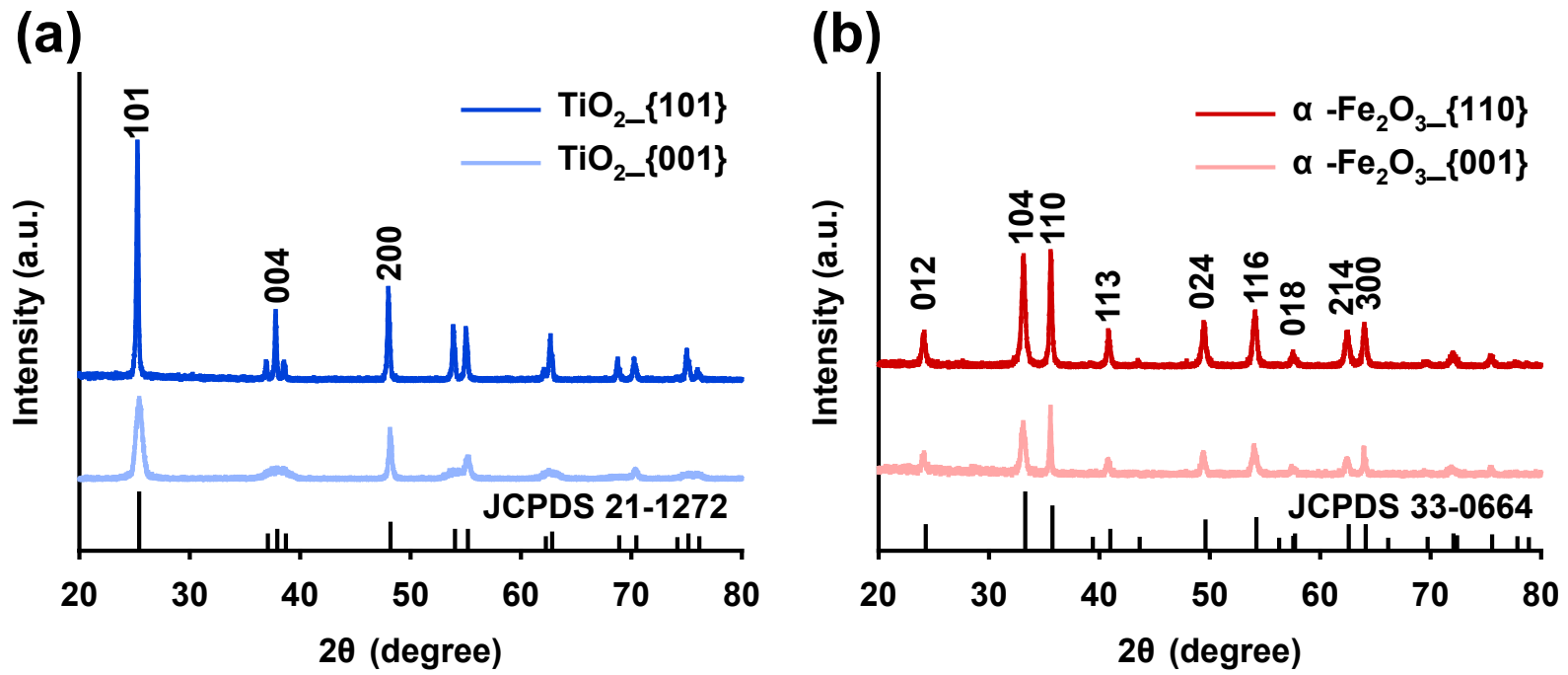

Figure S1. XRD patterns of different-faceted $\mathrm{TiO}_{2}$ (a) and $\alpha-\mathrm{Fe}_{2} \mathrm{O}_{3}$ (b) nanocrystals. 
(a)

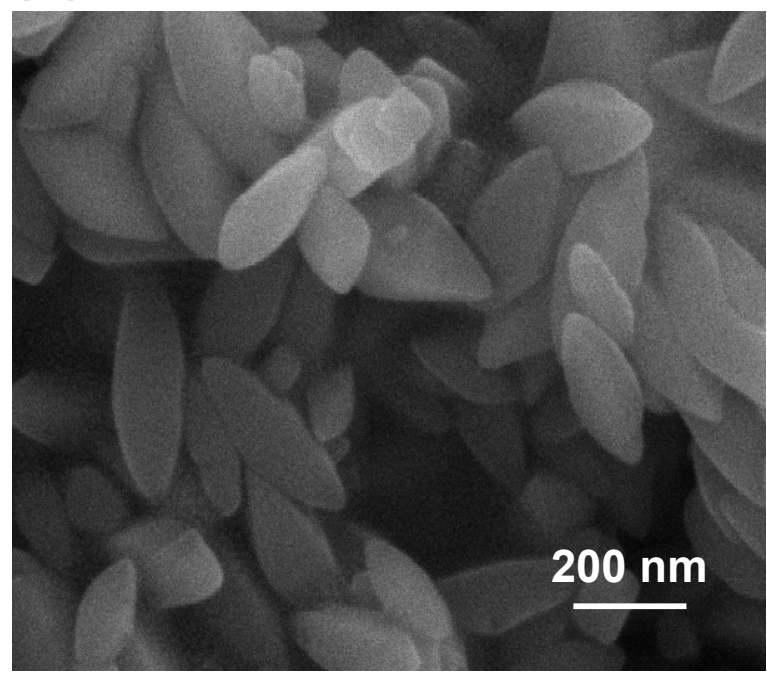

(c)

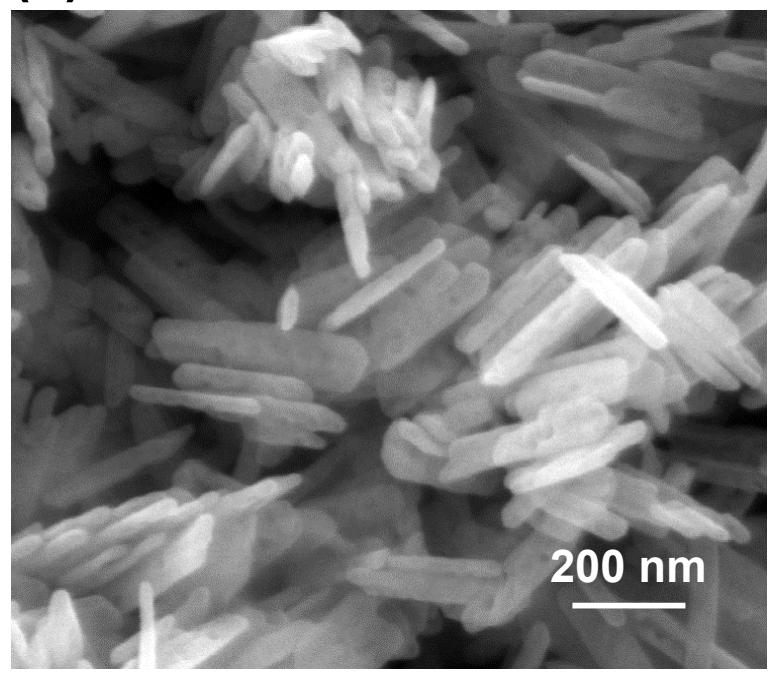

(b)

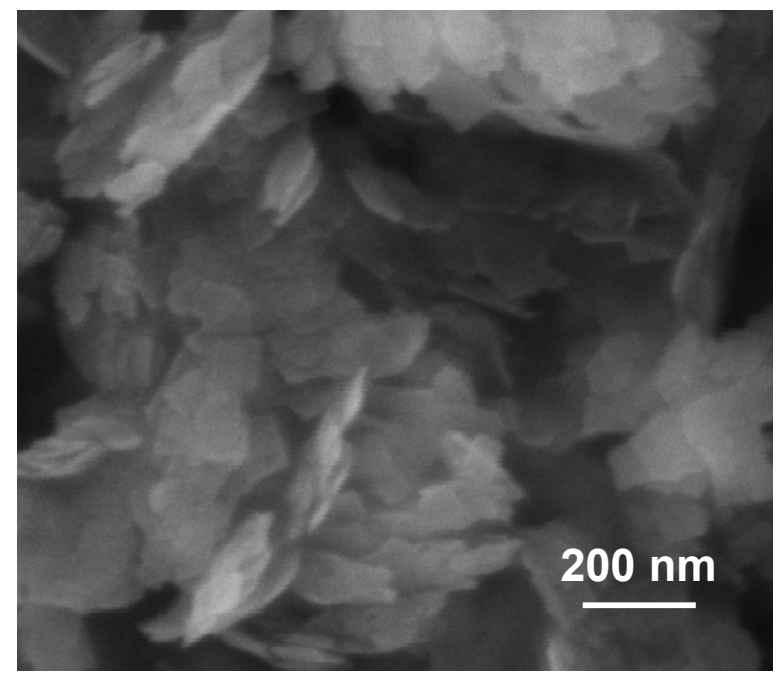

(d)

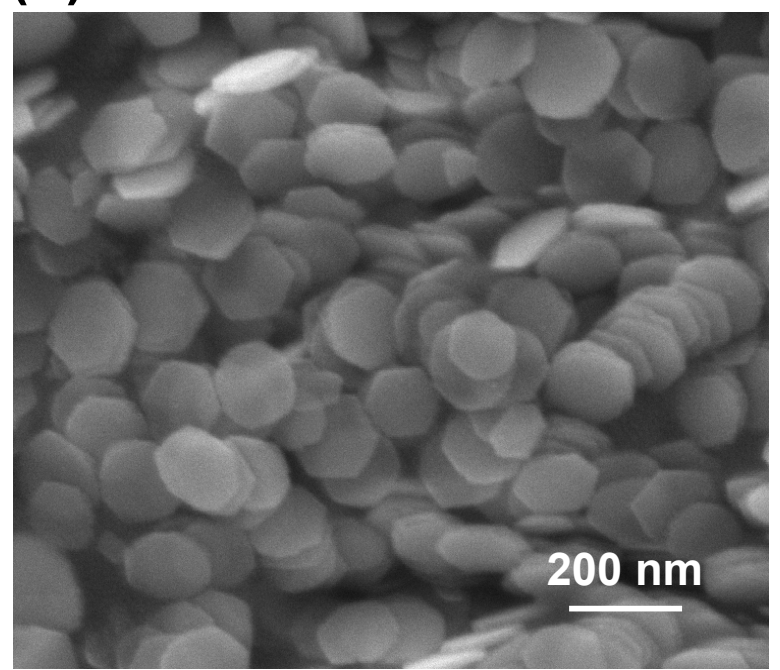

Figure S2. Scanning electron microscopy (SEM) images of $\mathrm{TiO}_{2}\{101\}$ (a), $\mathrm{TiO}_{2}\{001\}$ (b), $\alpha-\mathrm{Fe}_{2} \mathrm{O}_{3}\{110\}$ (c), $\alpha-\mathrm{Fe}_{2} \mathrm{O}_{3}\{001\}$ (d) nanocrystals. 

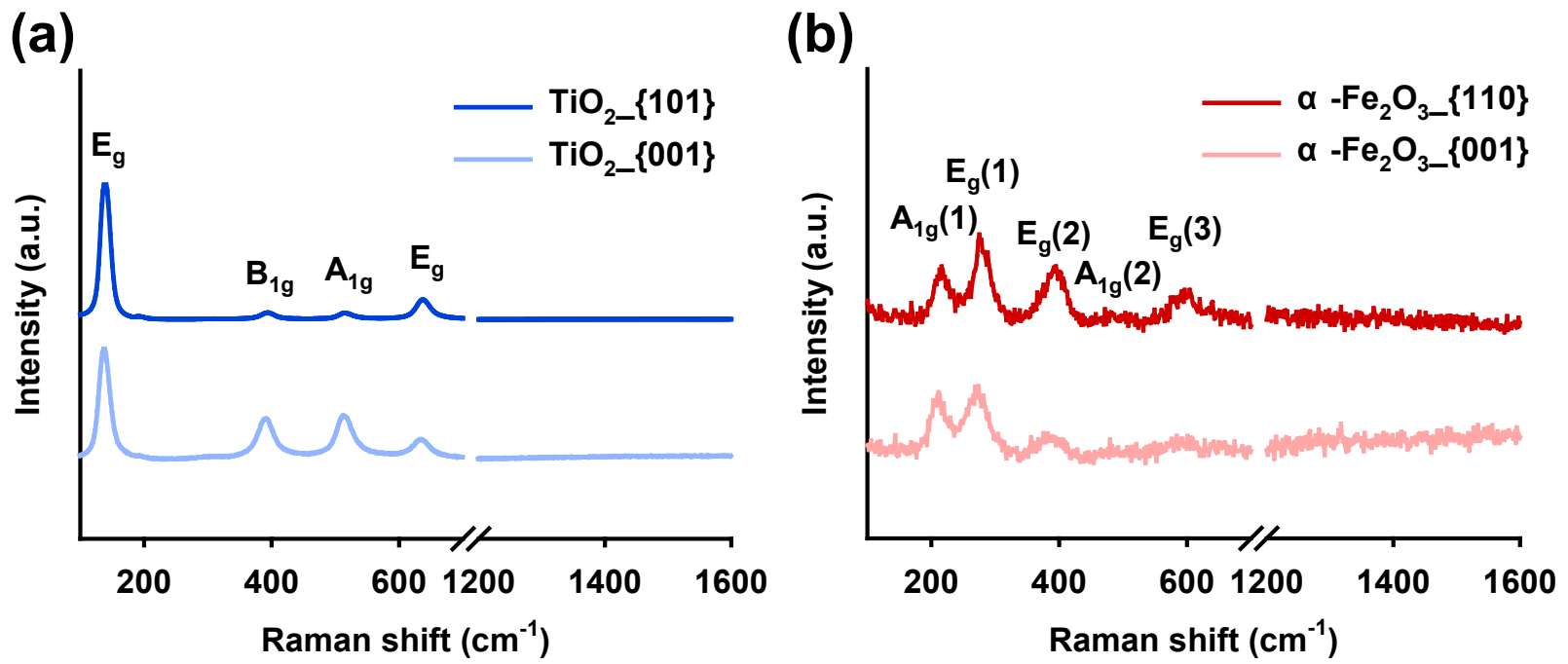

Figure S3. Raman spectra of different-faceted $\mathrm{TiO}_{2}$ (a) and $\alpha-\mathrm{Fe}_{2} \mathrm{O}_{3}$ (b) nanocrystals. 
(a)

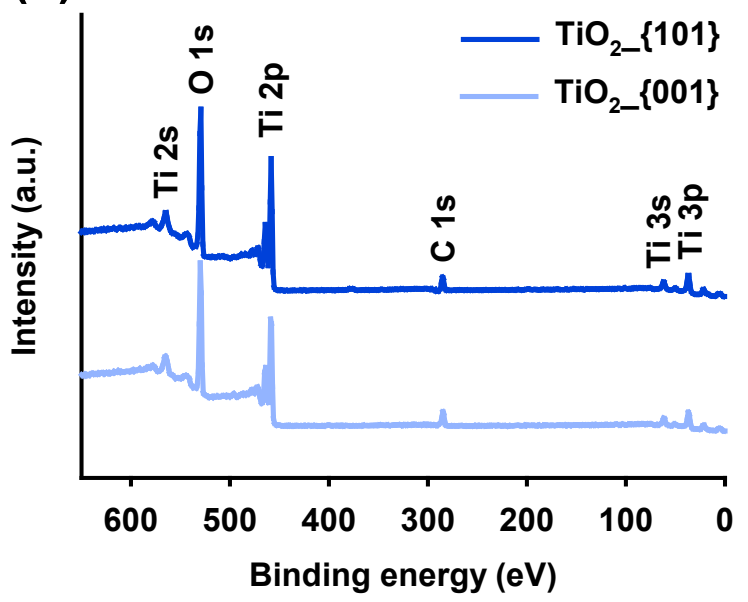

(c)

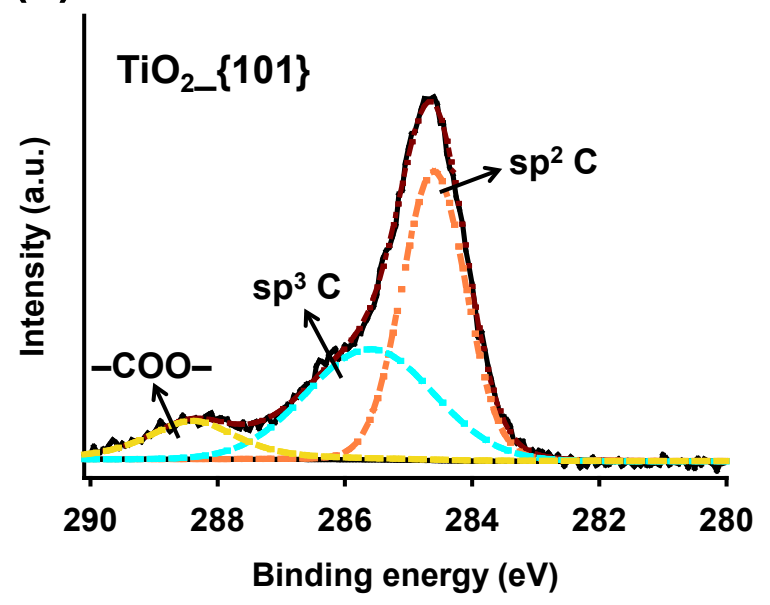

(e)

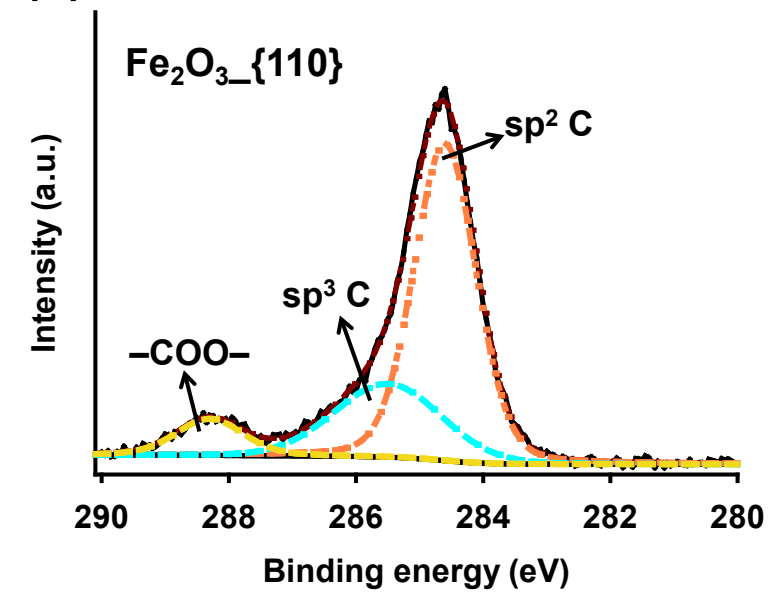

(b)

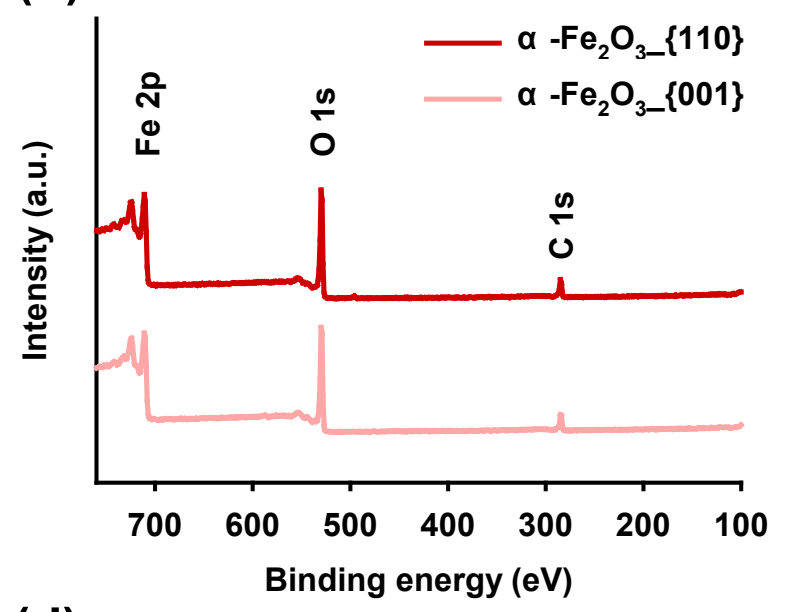

(d)

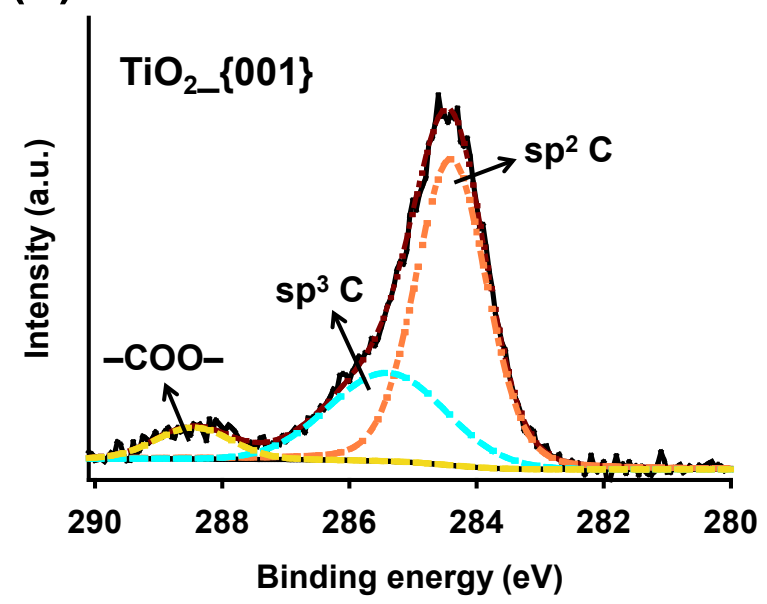

(f)

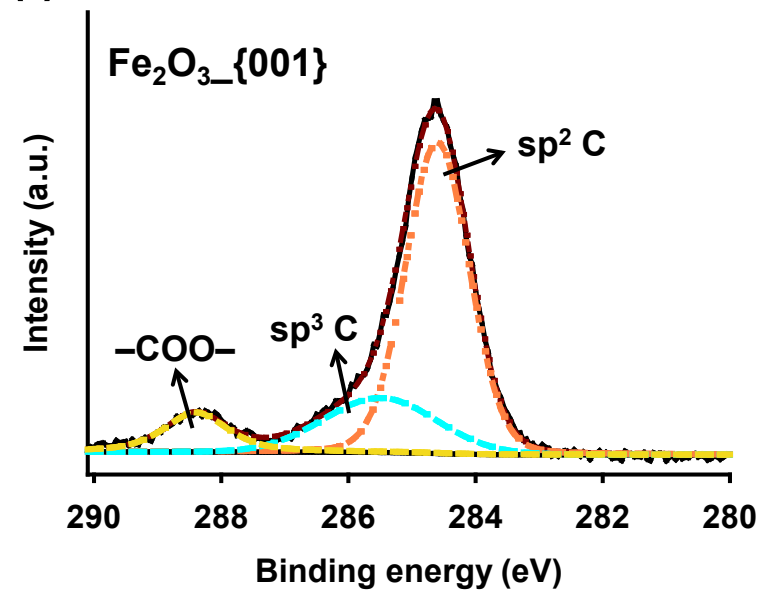

Figure S4. XPS spectra of different-faceted $\mathrm{TiO}_{2}$ (a) and $\alpha-\mathrm{Fe}_{2} \mathrm{O}_{3}$ (b) nanocrystals. Curve fits of $\mathrm{C} 1 \mathrm{~s}$ spectra of $\mathrm{TiO}_{2}\{101\}$ (c), $\mathrm{TiO}_{2}\{001\}$ (d), $\alpha-\mathrm{Fe}_{2} \mathrm{O}_{3}\{110\}$ (e) and $\alpha-\mathrm{Fe}_{2} \mathrm{O}_{3}\{001\}$ (f) nanocrystals. 


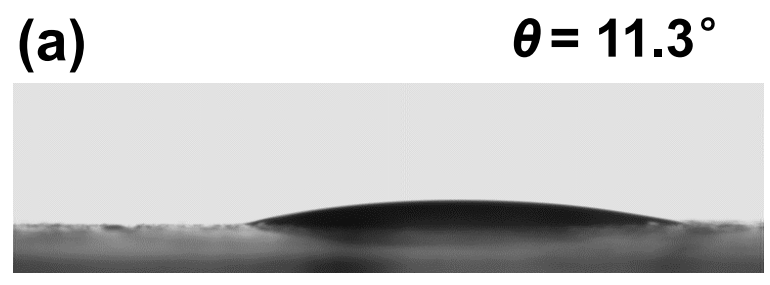

(b) $\quad \theta=15.8^{\circ}$

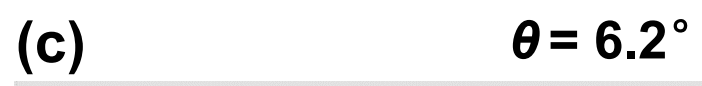

(d) $\quad \theta=30.0^{\circ}$
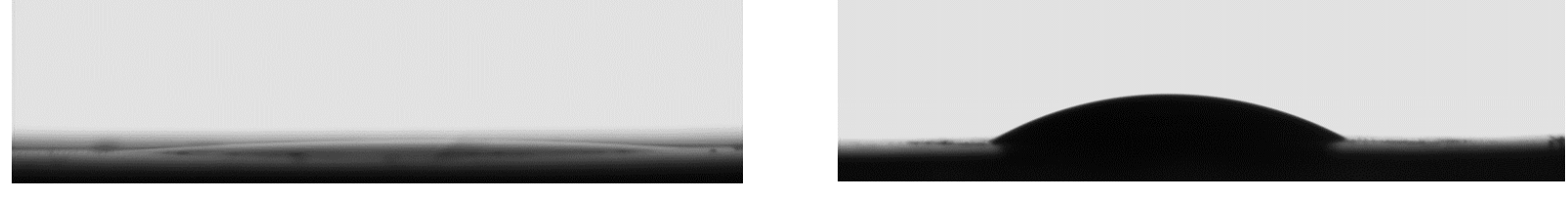

Figure S5. Photographs of water contact angles $(\theta)$ on the surfaces of $\mathrm{TiO}_{2}\{101\}$ (a), $\mathrm{TiO}_{2}\{001\}$ (b), $\alpha-\mathrm{Fe}_{2} \mathrm{O}_{3}\{110\}$ (c) and $\alpha-\mathrm{Fe}_{2} \mathrm{O}_{3}\{001\}$ (d) coated films. 
(a)

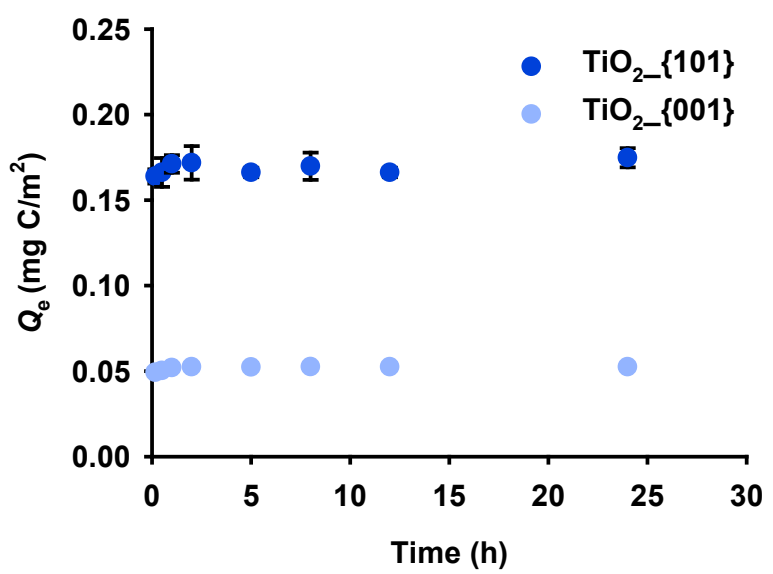

(c)

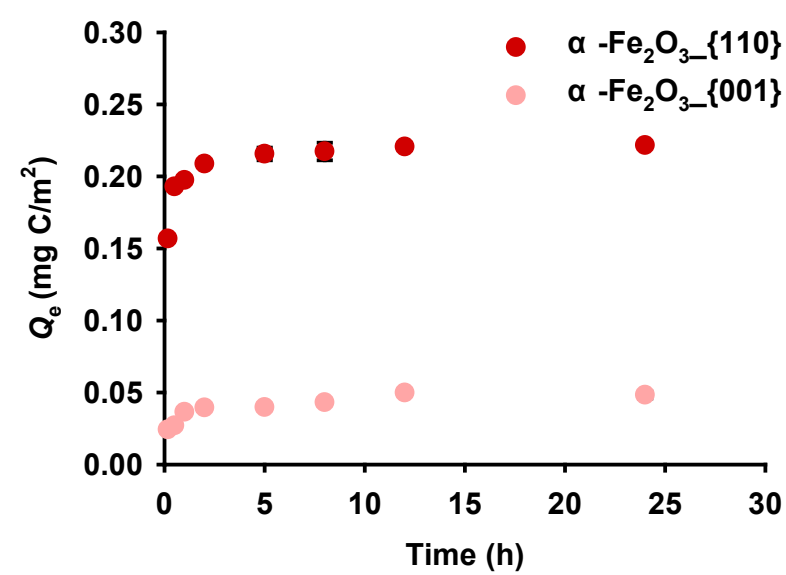

(b)

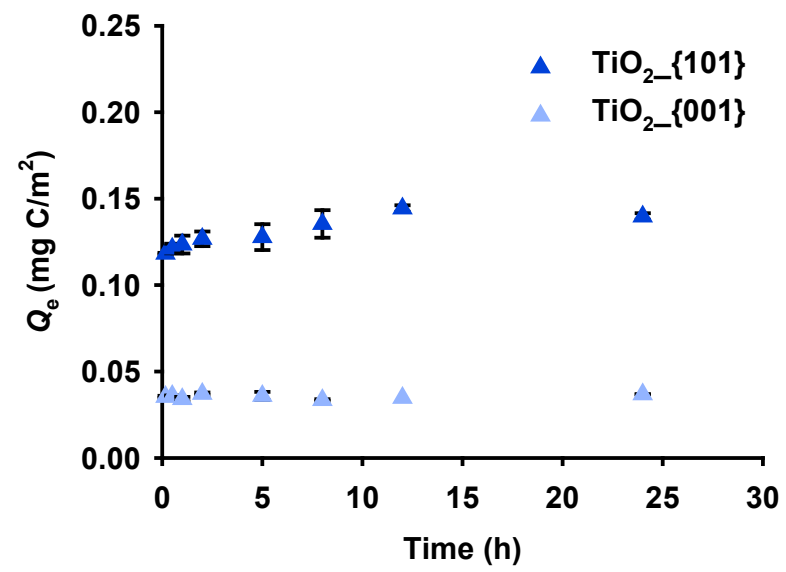

(d)

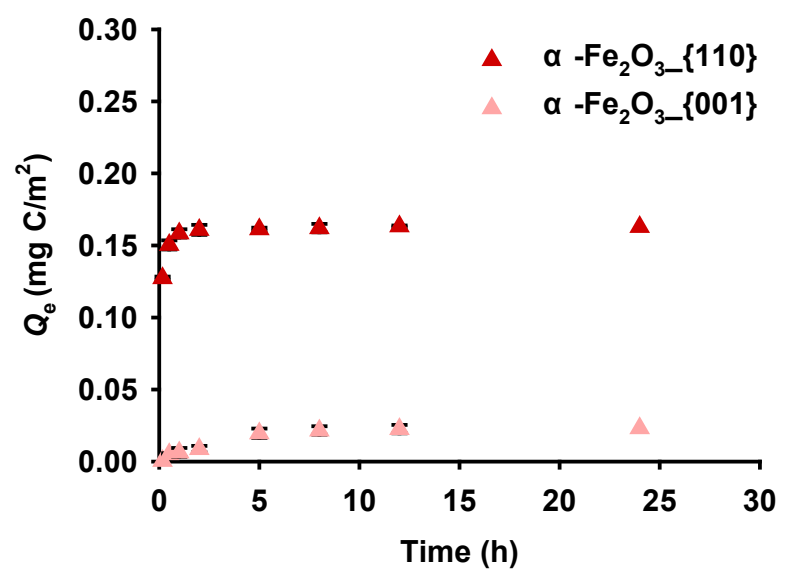

Figure S6. Adsorption kinetics of SRHA (a and c) and SRFA (b and d) on different-faceted $\mathrm{TiO}_{2}$ ( $\mathrm{a}$ and $\mathrm{b}$ ) and $\alpha-\mathrm{Fe}_{2} \mathrm{O}_{3}(\mathrm{c}$ and $\mathrm{d}$ ) nanocrystals. The error bars represent standard deviations of triplicate samples. 
(a)

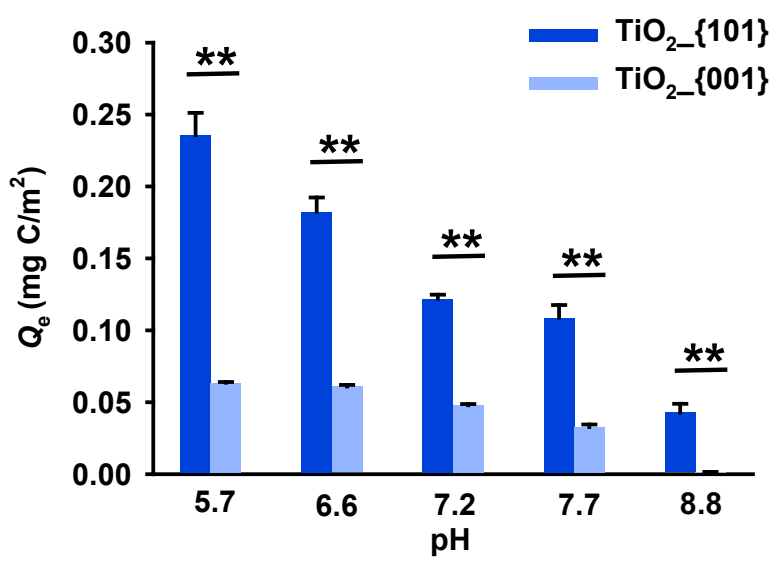

(c)

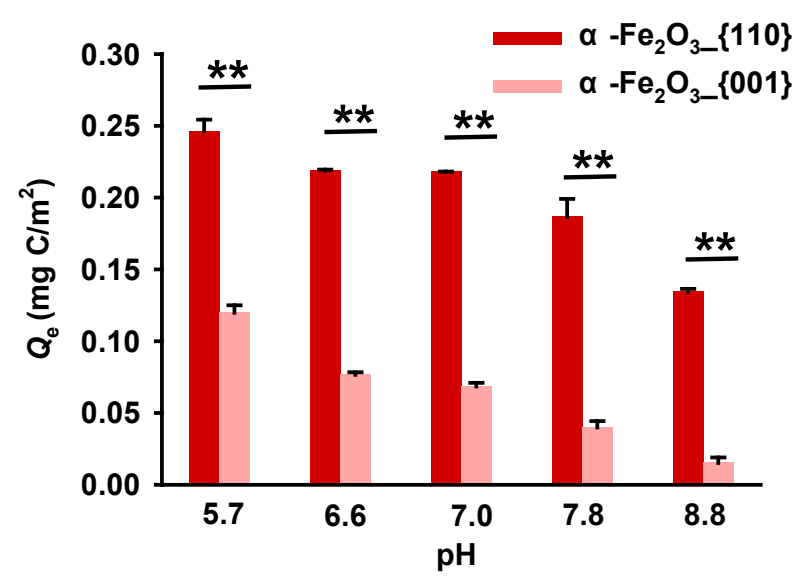

(b)

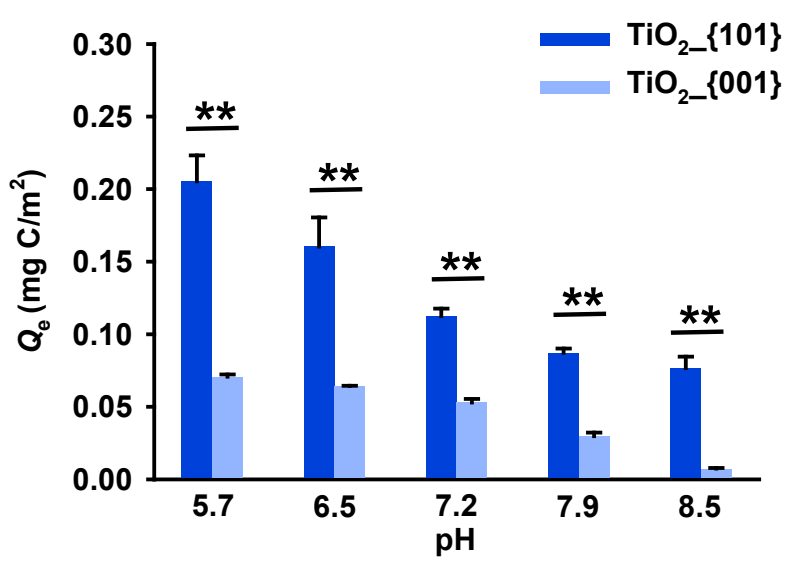

(d)

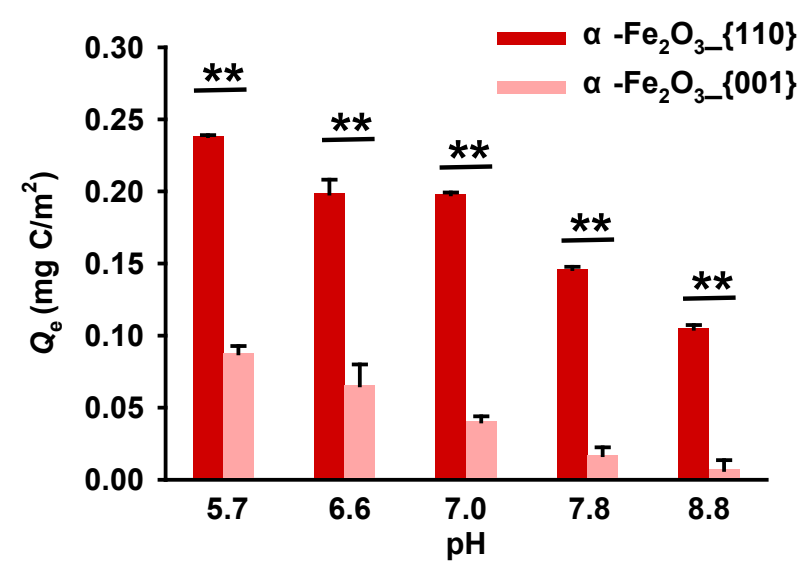

Figure S7. Adsorption amount of SRHA (a and c) and SRFA (b and d) on different-faceted $\mathrm{TiO}_{2}$ (a and b) and $\alpha-\mathrm{Fe}_{2} \mathrm{O}_{3}$ (c and d) nanocrystals at different $\mathrm{pH}$ conditions. The error bars represent standard deviations of triplicate samples. Statistical significance between groups: $\left({ }^{* *}\right) p<0.01$. 
(a)

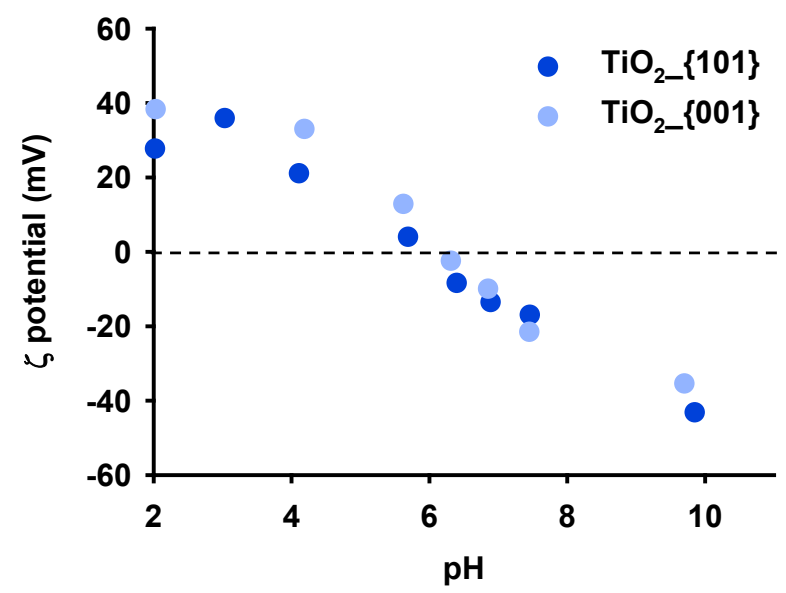

(b)

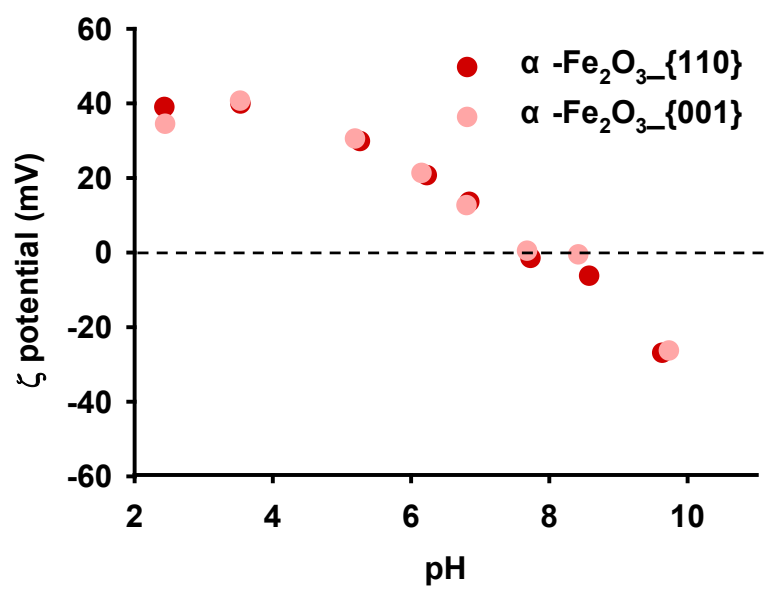

Figure S8. $\zeta$ potential values of different-faceted $\mathrm{TiO}_{2}$ (a) and $\alpha-\mathrm{Fe}_{2} \mathrm{O}_{3}$ (b) nanocrystals at different $\mathrm{pH}$ conditions in $0.01 \mathrm{M} \mathrm{NaNO}_{3}$ solution $\left(1 \mathrm{~g} \mathrm{~L}^{-1}\right.$ of nanocrystals). 
(a)
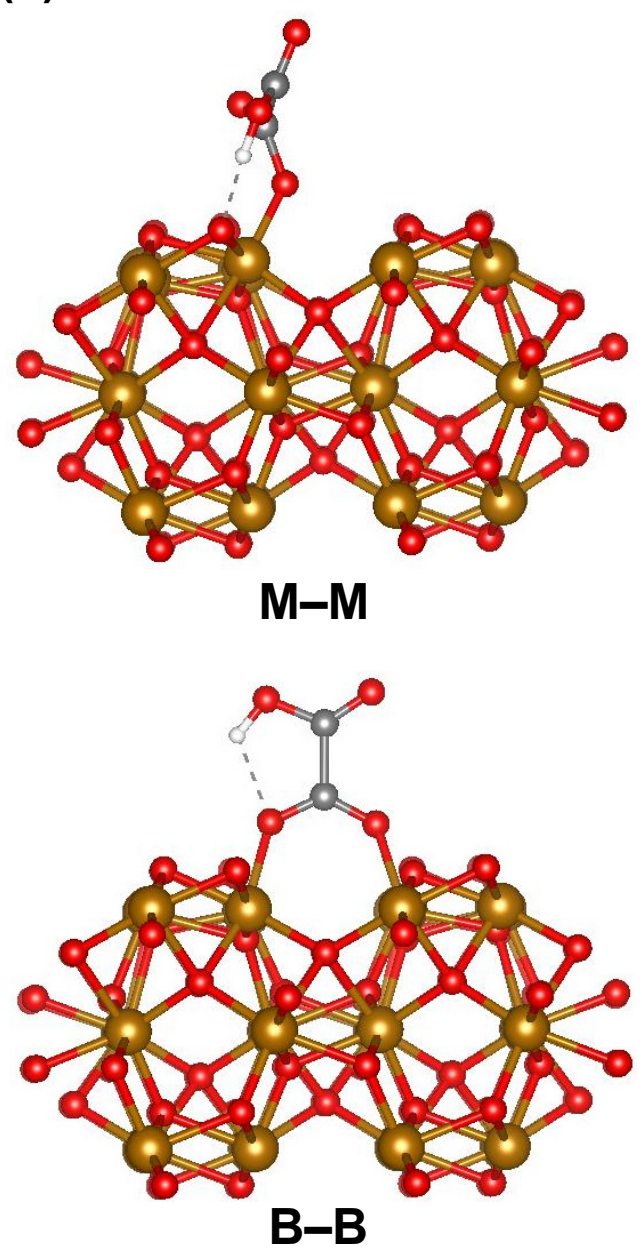

(b)
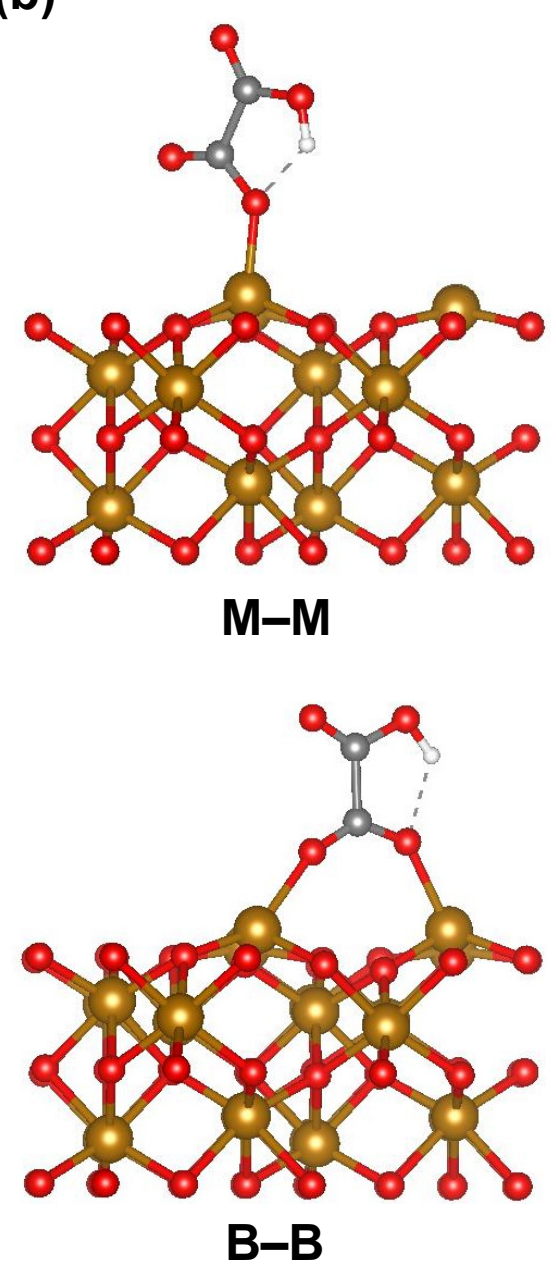

Figure S9. Optimized surface complex geometries of oxalic acid on $\{110\}$ (a) and $\{001\}$ (b) facets of hematite. $\mathrm{M}-\mathrm{M}$ and $\mathrm{B}-\mathrm{B}$ represent monodentate-mononuclear and bidentate-binuclear surface complexes, respectively. The brown, red, gray and white symbols represent the iron, oxygen, carbon and hydrogen atoms, respectively. 

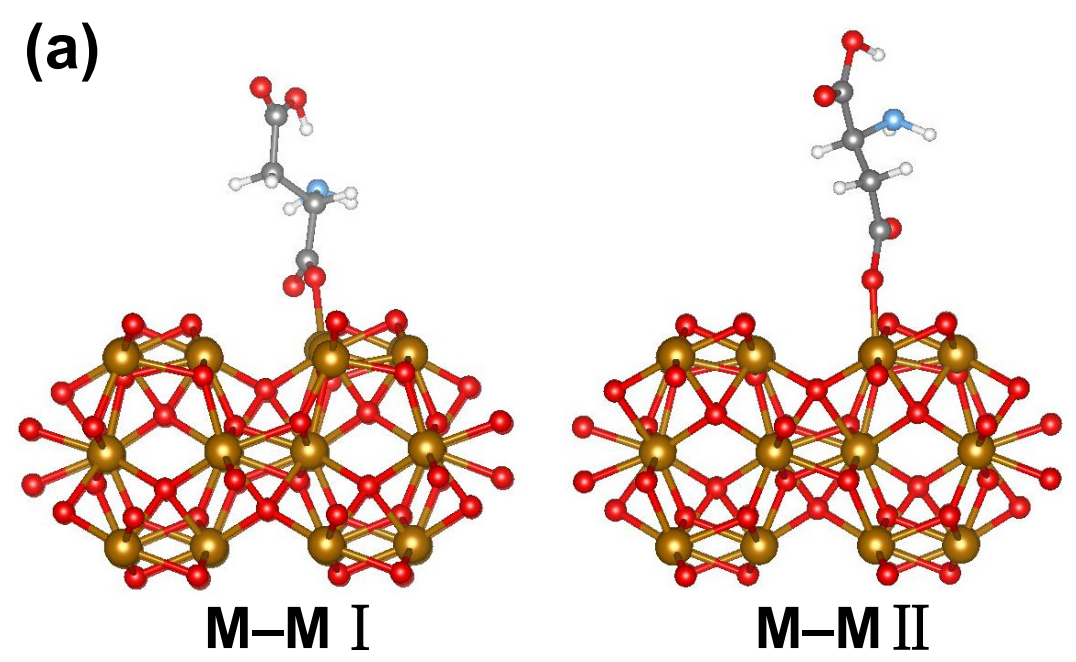

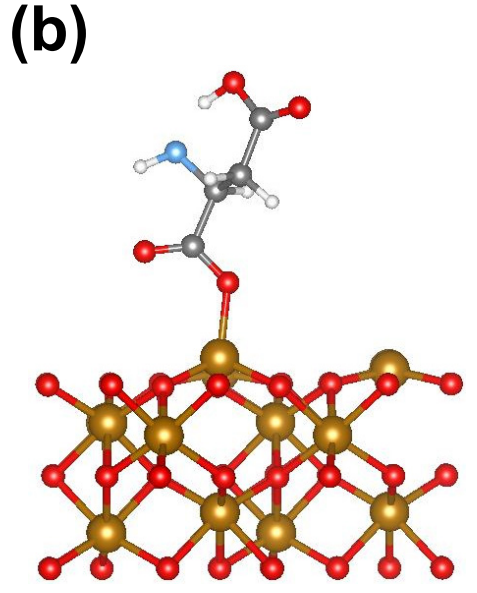

M-M I

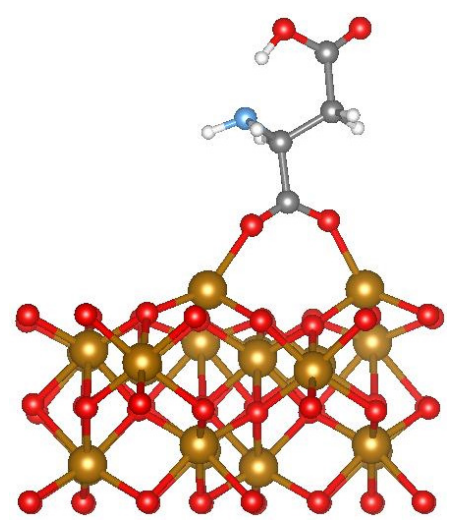

B-B I

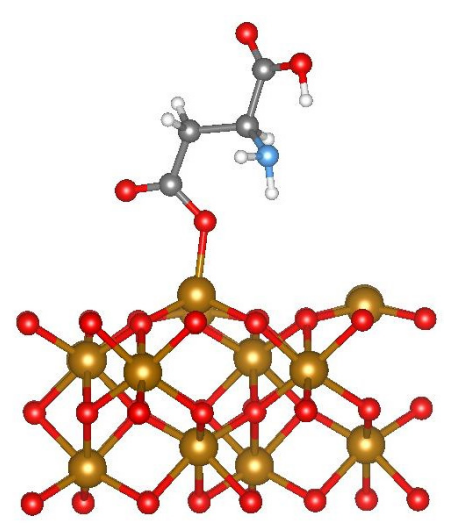

M-M II

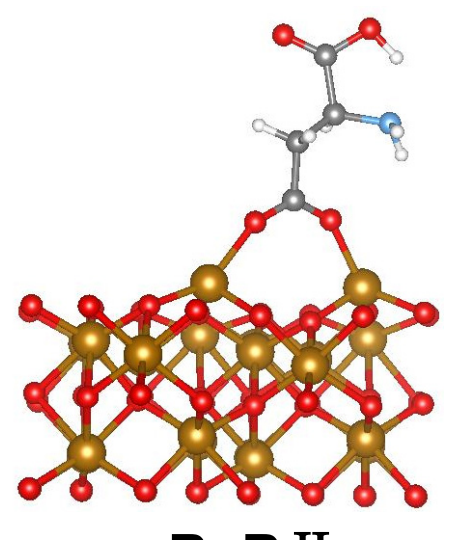

B-B II

Figure S10. Optimized surface complex geometries of aspartic acid on $\{110\}$ (a) and $\{001\}$ (b) facets of hematite. M-M and B-B (I: $\alpha$-carboxyl group, II: $\beta$-carboxyl group) represent monodentate-mononuclear and bidentate-binuclear surface complexes, respectively. The brown, red, gray, blue and white symbols represent the iron, oxygen, carbon, nitrogen and hydrogen atoms, respectively. 
(a)

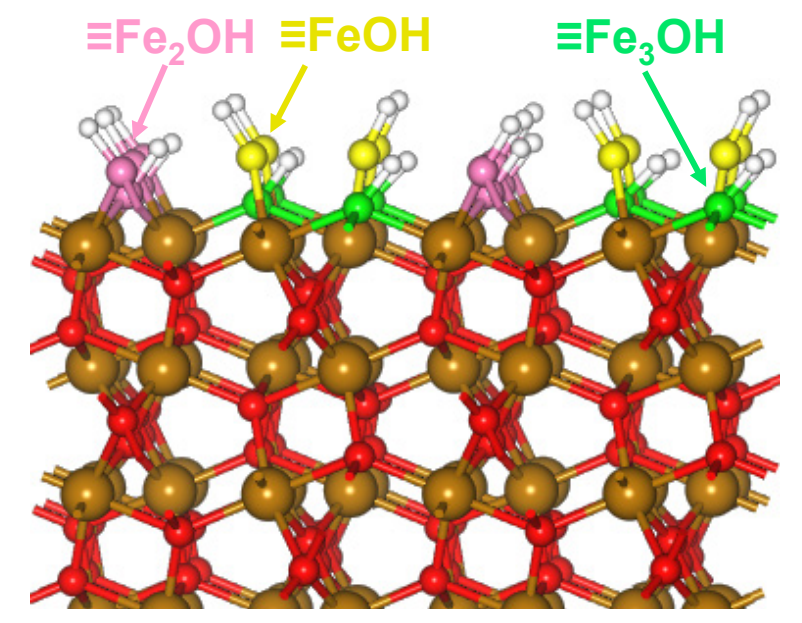

(b)

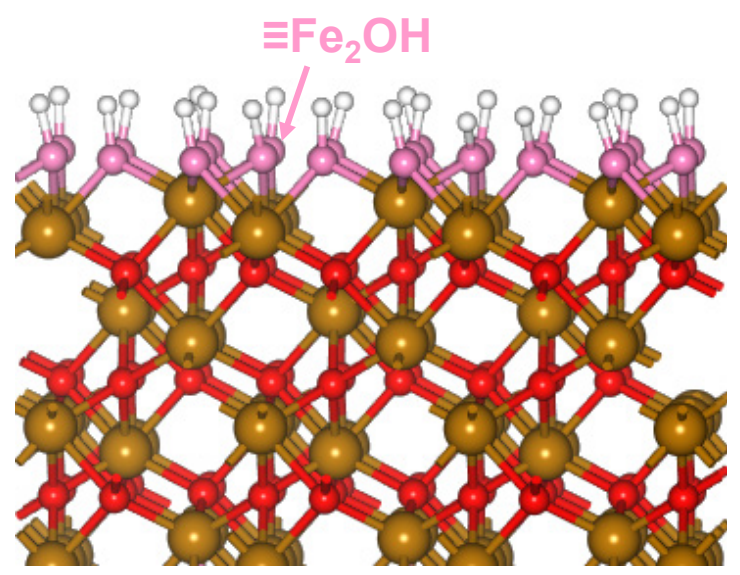

Figure S11. Side views of $\{110\}$ (a) and $\{001\}$ (b) facets of hematite. The brown, red and white symbols represent the iron, oxygen and hydrogen atoms, respectively. The yellow, pink and green symbols represent the oxygen atoms in singly $(\equiv \mathrm{FeOH})$, doubly $\left(\equiv \mathrm{Fe}_{2} \mathrm{OH}\right)$, or triply $\left(\equiv \mathrm{Fe}_{3} \mathrm{OH}\right)$ surface hydroxyl functional groups, respectively. 

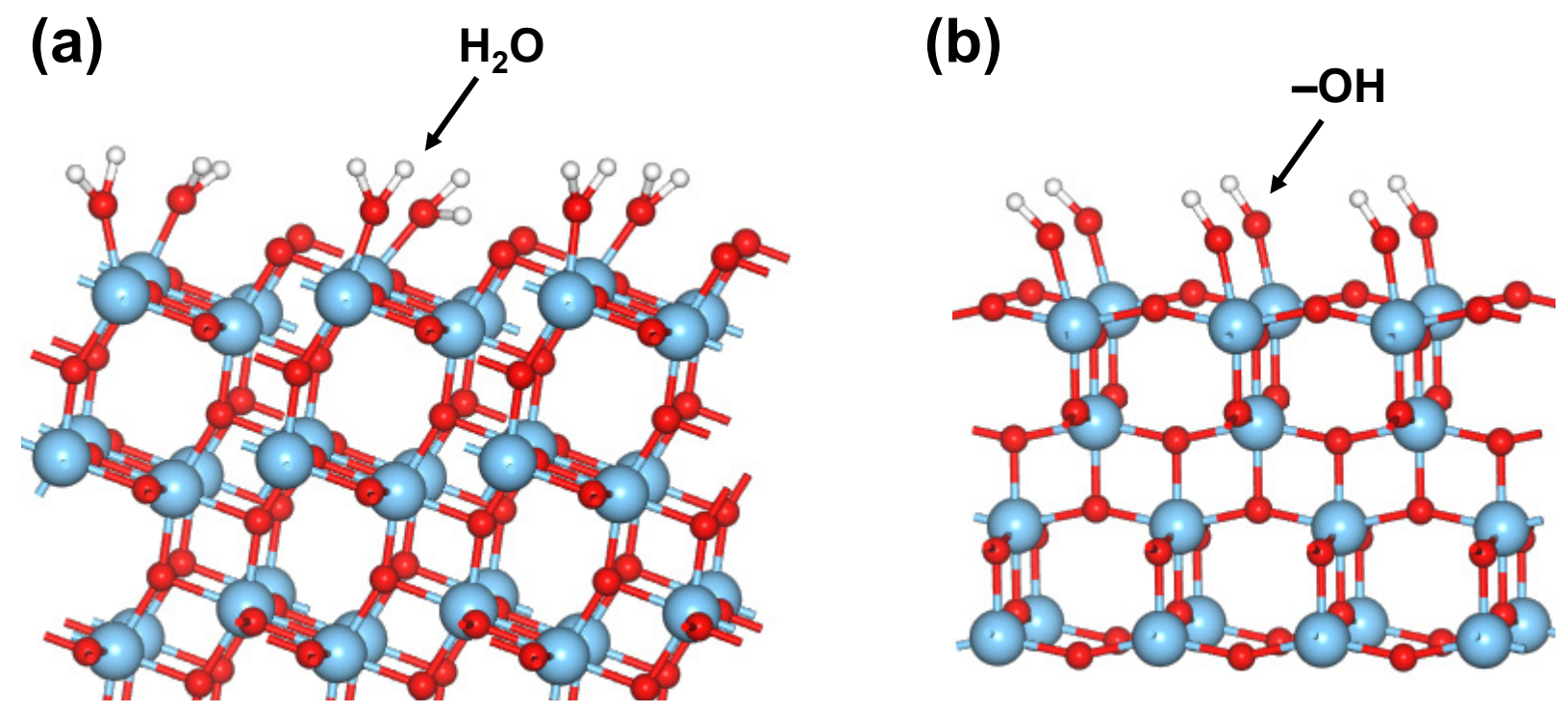

Figure S12. Side views of $\{101\}$ (a) and $\{001\}$ (b) facets of anatase. The blue, red and white symbols represent the titanium, oxygen and hydrogen atoms, respectively. Water molecules adsorb to anatase $\{101\}$ facet without dissociation, and to anatase $\{001\}$ facet with dissociation. 


\section{REFERENCES}

1. Li, T.; Shen, Z. L.; Shu, Y. L.; Li, X. G.; Jiang, C. J.; Chen, W., Facet-dependent evolution of surface defects in anatase $\mathrm{TiO}_{2}$ by thermal treatment: implications for environmental applications of photocatalysis. Environ. Sci.: Nano 2019, 6 (6), 1740-1753.

2. Zhang, H.; Wang, W. M.; Zhao, H. X.; Zhao, L. X.; Gan, L. Y.; Guo, L. H., Facet-mediated interaction between humic acid and $\mathrm{TiO}_{2}$ nanoparticles: implications for aggregation and stability kinetics in aquatic environments. Environ. Sci.: Nano 2019, 6 (6), 1754-1764.

3. Huang, X. P.; Hou, X. J.; Song, F. H.; Zhao, J. C.; Zhang, L. Z., Facet-dependent Cr(VI) adsorption of hematite nanocrystals. Environ. Sci. Technol. 2016, 50 (4), 1964-1972.

4. Li, C. H.; Koenigsmann, C.; Ding, W. D.; Rudshteyn, B.; Yang, K. R.; Regan, K. P.; Konezny, S. J.; Batista, V. S.; Brudvig, G. W.; Schmuttenmaer, C. A.; Kim, J. H., Facet-dependent photoelectrochemical performance of $\mathrm{TiO}_{2}$ nanostructures: an experimental and computational study. J. Am. Chem. Soc. 2015, 137 (4), 1520-1529.

5. Yang, H. G.; Sun, C. H.; Qiao, S. Z.; Zou, J.; Liu, G.; Smith, S. C.; Cheng, H. M.; Lu, G. Q., Anatase $\mathrm{TiO}_{2}$ single crystals with a large percentage of reactive facets. Nature 2008, 453 (7195), $638-641$.

6. Perdew, J. P.; Burke, K.; Ernzerhof, M., Generalized gradient approximation made simple. Phys. Rev. Lett. 1996, 77 (18), 3865-3868.

7. Hammer, B.; Hansen, L. B.; Norskov, J. K., Improved adsorption energetics within density-functional theory using revised Perdew-Burke-Ernzerh of functionals. Phys. Rev. B 1999, 59 (11), 7413-7421.

8. Blochl, P. E., Projector augmented-wave method. Phys. Rev. B 1994, 50 (24), 17953-17979.

9. Kresse, G.; Joubert, D., From ultrasoft pseudopotentials to the projector augmented-wave 
method. Phys. Rev. B 1999, 59 (3), 1758-1775.

10. Monkhorst, H. J.; Pack, J. D., Special points for Brillouin-zone integrations. Phys. Rev. B 1976, $13(12), 5188-5192$.

11. Wan, W. J.; Nie, X. W.; Janik, M. J.; Song, C. S.; Guo, X. W., Adsorption, dissociation, and spillover of hydrogen over $\mathrm{Au} / \mathrm{TiO}_{2}$ catalysts: the effects of cluster size and metal-support interaction from DFT. J. Phys. Chem. C 2018, 122 (31), 17895-17916.

12. Pabisiak, T.; Kiejna, A., Fe adsorption on hematite $\left(\alpha-\mathrm{Fe}_{2} \mathrm{O}_{3}\right)(0001)$ and magnetite $\left(\mathrm{Fe}_{3} \mathrm{O}_{4}\right)$ (111) surfaces. J. Chem. Phys. 2014, 141 (13), 134707.

13. Czelej, K.; Zemla, M. R.; Spiewak, P.; Wejrzanowski, T.; Kurzydlowski, K. J., Atomic-scale computational design of hydrophobic RE surface-doped $\mathrm{Al}_{2} \mathrm{O}_{3}$ and $\mathrm{TiO}_{2}$. Phys. Chem. Chem. Phys. 2017, 19 (31), 21119-21126.

14. Carchini, G.; Garcia-Melchor, M.; Lodziana, Z.; Lopez, N., Understanding and tuning the intrinsic hydrophobicity of rare earth oxides: a DFT plus U study. ACS Appl. Mater. Interfaces 2016, $8(1), 152-160$.

15. Young, T., III. An essay on the cohesion of fluids. Philos. Trans. R. Soc. London 1805, 95, $65-87$.

16. Kuna, J. J.; Voitchovsky, K.; Singh, C.; Jiang, H.; Mwenifumbo, S.; Ghorai, P. K.; Stevens, M. M.; Glotzer, S. C.; Stellacci, F., The effect of nanometre-scale structure on interfacial energy. Nat. Mater. 2009, 8 (10), 837-842.

17. Li, D.; Neumann, A. W., A reformulation of the equation of state for interfacial-tensions. $J$. Colloid Interface Sci. 1990, 137 (1), 304-307.

18. Correia, N. T.; Ramos, J. J. M.; Saramago, B. J. V.; Calado, J. C. G., Estimation of the surface tension of a solid: application to a liquid crystalline polymer. J. Colloid Interface Sci. 
1997, 189 (2), 361-369.

19. Coble, P. G.; Del Castillo, C. E.; Avril, B., Distribution and optical properties of CDOM in the Arabian Sea during the 1995 Southwest Monsoon. Deep-Sea Res. Part II-Top. Stud. Oceanogr. 1998, 45 (10-11), 2195-2223.

20. Coble, P. G., Marine optical biogeochemistry: the chemistry of ocean color. Chem. Rev. 2007, 107 (2), 402-418.

21. Chen, W.; Westerhoff, P.; Leenheer, J. A.; Booksh, K., Fluorescence excitation-emission matrix regional integration to quantify spectra for dissolved organic matter. Environ. Sci. Technol. 2003, $37(24), 5701-5710$.

22. Wu, J.; Zhang, H.; He, P. J.; Shao, L. M., Insight into the heavy metal binding potential of dissolved organic matter in MSW leachate using EEM quenching combined with PARAFAC analysis. Water Res. 2011, 45 (4), 1711-1719.

23. Ateia, M.; Apul, O. G.; Shimizu, Y.; Muflihah, A.; Yoshimura, C.; Karanfil, T., Elucidating adsorptive fractions of natural organic matter on carbon nanotubes. Environ. Sci. Technol. 2017, 51 (12), 7101-7110.

24. Romera-Castillo, C.; Chen, M. L.; Yamashita, Y.; Jaffe, R., Fluorescence characteristics of size-fractionated dissolved organic matter: implications for a molecular assembly based structure? Water Res. 2014, 55, 40-51.

25. Stedmon, C. A.; Markager, S.; Bro, R., Tracing dissolved organic matter in aquatic environments using a new approach to fluorescence spectroscopy. Mar. Chem. 2003, 82 (3-4), $239-254$.

26. Zhang, Y. L.; van Dijk, M. A.; Liu, M. L.; Zhu, G. W.; Qin, B. Q., The contribution of phytoplankton degradation to chromophoric dissolved organic matter (CDOM) in eutrophic 
shallow lakes: field and experimental evidence. Water Res. 2009, 43 (18), 4685-4697.

27. Zhang, Y. L.; Yin, Y.; Feng, L. Q.; Zhu, G. W.; Shi, Z. Q.; Liu, X. H.; Zhang, Y. Z.,

Characterizing chromophoric dissolved organic matter in Lake Tianmuhu and its catchment basin using excitation-emission matrix fluorescence and parallel factor analysis. Water Res. 2011, 45 (16), 5110-5122.

28. Kowalczuk, P.; Durako, M. J.; Young, H.; Kahn, A. E.; Cooper, W. J.; Gonsior, M., Characterization of dissolved organic matter fluorescence in the South Atlantic Bight with use of PARAFAC model: interannual variability. Mar. Chem. 2009, 113 (3-4), 182-196. 